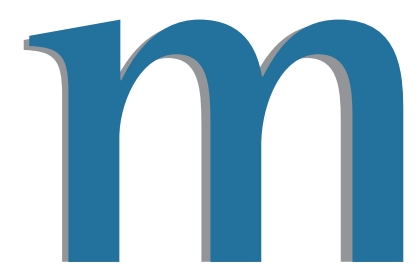

\title{
A recriação discursiva da tecnologia em Oswald de Andrade: uma leitura não convencional
}

\author{
Angela Maria Rubel Fanini \\ Universidade Tecnológica Federal do Paraná/Uniandrade, Brasill \\ http://orcid.org/0000-0001-7088-1251
}

\section{RESUMO}

A pesquisa focou a questão da tecnologia importada trazida para o Brasil, mormente da Europa, no período da República Velha e investigou como Oswald de Andrade integrou discursivamente essa realidade tecnológica em sua obra Manifesto Pau-Brasil (1924). Oswald recria essa realidade de maneira dialógica, elaborando um retrato do país em que a cor local se manifesta a partir das tradições que remontam ao passado colonial e imperial, abarcando também uma certa cultura popular e do cotidiano em que a religiosidade, as crenças, as superstições entram em confronto e em sintonia com a modernidade tecnológica. Desse confronto, surge uma certa identidade nacional fruto de dimensões polarizadas, mas que se interpenetram, sem se excluírem. O recurso da dialogia é intensificado por uma perspectiva em que se manifestam os impasses e disjunções dessa polarização, como também de sua orgânica coexistência. Exploramos a articulação entre universo técnico e linguagem literária, tema pouco tratado nas leituras críticas da área de Letras.

PALAVRAS-CHAVE: Tecnologia; Discurso literário; Oswald de Andrade.

\section{The discursive recreation of technology in Oswald de Andrade:}

\section{a non-conventional reading}

\begin{abstract}
The research focused on the issue of imported technology brought to Brazil, mainly from Europe, during the Old Republic period and investigated how Oswald de Andrade (1890-1954) discursively integrated this technological reality in his work Manifesto Pau-Brasil (1924). Oswald recreates this reality in a dialogical way, elaborating a portrait of the country in which the local color manifests itself from traditions that go back to the colonial and imperial past, also encompassing a certain popular and everyday culture in which religiosity, beliefs, superstitions clash that are in opposition to technological modernity. From this confrontation, tense and dynamic, a certain national identity emerges as a result of polarized dimensions, but that interpenetrate, without excluding themselves. The dialogic resource is intensified by a perspective in which the impasses, unevenness and disjunctions of this polarization are manifested, as well as its organic coexistence. We explored the articulation between the technical universe and literary language, a theme that is barely dealt with in critical readings in the field of Literature studies.
\end{abstract}

KEYWORDS: Technology; Literary discourse; Oswald de Andrade. 


\section{Oswald de Andrade, cultura e economia de exportação: uma articulação pouco convencional}

O literato, no dizer de Antonio Candido (1981), volta-se para a realidade nacional, recriando-a esteticamente. Percebe a Literatura Brasileira como um discurso empenhado e interessado sobre a realidade local. Candido (1987) destaca também que os escritores elaboram suas obras entre a dependência e a liberdade em relação às formas estéticas e às ideias importadas da Europa. Alguns escritores, percebendo a inferioridade do meio local, afastam-se dele, vivendo em torres de marfim; outros, observando as dissonâncias, elaboram obras no intuito de transformar o meio em cenário europeu, frisando apenas o atraso nacional, e outros, ainda, não ignoram as discrepâncias, mas as problematizam em uma chave interacionista em que o local vai surgindo mediante as articulações entre a liberdade e a dependência de modelos importados. Parte da cultura nacional nasce como fruto de uma série de impasses em que os escritores lidam de formas diversas com formas estéticas parcialmente alheias à realidade local.

Bosi (1992) também discute essa articulação entre o local e o importado, trazendo a ideia de filtragem em que formas culturais exógenas, advindas da Europa e dos Estados Unidos, mormente, passam por uma adaptação no solo brasileiro. O crítico discute o corte de classe, em que a elite filtra o que lhe convém em detrimento de ganhos para o geral da população. Schwarz (2000) também empreende essa discussão, problematizando se as ideias estão fora do lugar, enfatizando o corte de classe. Seguindo esses autores, podemos refletir de que maneira os discursos sociais e as formas literárias, originários majoritariamente das sociedades europeias, adaptam-se ou não à realidade local. As ideias estarem ou não no lugar é a abordagem foco nessas produções. Para o estudioso de nossa literatura, os textos referidos são procedentes para se aclarar essa questão.

Oswald de Andrade foi um dos líderes da Semana de Arte Moderna, realizada em São Paulo, 1922, cujo propósito maior era propor uma nova linguagem artística, amparada pelas inovações formais e conteudísticas presentes nas vanguardas europeias (Futurismo, Expressionismo, Dadaísmo, Surrealismo). Esse trânsito entre as estéticas importadas não se dava de forma ingênua ou submissa. A obra de Oswald pode ser lida a partir desse prisma de compromisso entre as vanguardas europeias, sem perder o foco no referente nacional. O escritor foi homem de seu tempo e não alheio ao que se passava na Europa em termos de uma nova linguagem para dizer as coisas ${ }^{1}$. Oswald não permaneceu somente na inovação técnica da linguagem, mas foi responsável por plasmar uma certa visão de mundo sobre a identidade nacional tecnológica, aclarando como essa realidade material era filtrada pelo cenário cultural. Infraestrutura importada e superestrutura enraizada nos hábitos e costumes brasileiros entram em dissonância e consonância nas lentes oswaldianas.

\footnotetext{
1 Machado (2008), no século XIX, em texto crítico, Notícia da atual literatura brasileira: instinto de nacionalidade (1873) enfatiza que todo escritor é homem de seu tempo e país, destacando o relevante papel do espaço e do tempo que instituem a posição axiológica do discurso literário.
} 


\section{Corpus: as articulações entre infraestrutura e superestrutura}

Para este artigo, analisaremos trechos do Manifesto Pau-Brasil2 em que percebemos essa tensão entre ideias e tecnologia importadas e o contexto brasileiro. Nessa obra, observamos que a dimensão imaterial da linguagem literária se encontra atrelada ao universo material brasileiro, recriando-o. Essa relação com o referente antes o refrata que o reflete ${ }^{3}$, pois o discurso oswaldiano não se pretende fotográfico do real, mas o vê a partir de lentes valorativas. O contexto nacional vai surgindo a partir dos opostos que se interpenetram em uma relação dialógica que se vincula, em parte, a uma perspectiva "antropofágica", que consiste em não descartar o novo, o advento técnico, o ideário importado, mas mobilizá-lo mediante um chão histórico brasileiro, cujo cronotopo ${ }^{4}$ recupera um espaço e um tempo próprios de nossa História. O termo antropofágico não ocorre no Manifesto Pau-Brasil. Esse termo aparece no Manifesto antropófago (1928) especificamente, mas a cosmovisão a que alude não se restringe exclusivamente a esta obra. Oswald retoma o termo, remontando-o à cultura indígena, uma de nossas matrizes de formação e, com ela, fortalece a cor local em diálogo e dissonância com a cultura de importação. A antropofagia é um dos pilares axiológicos que constitui a visão de mundo do autor e fundamenta o seu posicionamento enquanto intelectual que responde a questões humanas e brasileiras de sua época. A visão antropofágica se delineia na obra de Oswald em diversos momentos nos quais ocorre de modo específico. No Manifesto Pau-Brasil já se manifesta, mas não com toda a carga ideológica que é apresentada no Manifesto Antropófago. No entanto, a perspectiva antropofágica de reunir os contrários, evitando a opção polarizada e dicotomizada é uma constante na obra do escritor. Nesse passo é que verificamos, no corpus lido e analisado, uma certa perspectiva antropofágica da tecnologia nacional. Todavia, a axiologia antropofágica plena deverá ser estudada em Manifesto antropófago quando o escritor, de modo definitivo, esclarece e apresenta essa perspectiva, mas que já se delineava na obra em tela. A relação dialógica ${ }^{5}$ entre cronotopos diversos possibilita criar uma certa identidade brasileira, mas em interação com outras culturas advindas de fora. Nesse novo caminho entre o importado e o local, há uma tomada de posição axiológica e o real vai sendo elaborado mediante juízos de valor que se afastam de uma perspectiva realista de colagem entre as palavras e as coisas. Para demonstrar, neste artigo, essa

\footnotetext{
${ }^{2}$ Obra de domínio público consultada na Internet, informada em Referências, neste documento. As citações se referem a este documento.

3 Os termos reflexão e refração tomamos a Bakhtin; Volochinov (1986) que percebem a linguagem enquanto discurso na práxis da existência. A linguagem parte do real, mas não é neutra em relação ao mesmo. Formaliza-o em consonância com os valores e ideias de uma época e de seu emissor. O discurso reflete o real, vinculado a ele de modo orgânico, mas o refrata, pois é uma mediação ideológica entre o emissor e as coisas.

${ }^{4}$ Tomamos o termo a Bakhtin, cuja obra de orientação materialista, percebe o discurso constituído em suas coordenadas históricas a que chama de cronotopo. Todo ato enunciativo parte de algum lugar e tempo. A dimensão espacial e temporal, não são somente físicas, mas políticas, pois cada cronotopo se constitui de certos valores e ideologias. É improcedente citar apenas uma obra do teórico russo, neste trabalho, pois a categoria cronotopo percorre toda sua produção, visto que a linguagem somente ocorre como discurso e esse é sempre situado historicamente em coordenadas, não só geográficas, mas ideológicas.

${ }^{5}$ O termo dialógico extraímos do Círculo russo que trata da dialogia como fator preponderante para se perceber as inter-relações discursivas e culturais. O dialogismo é categoria fundante para os teóricos e nem sempre indica um consenso entre formas culturais e discursivas que se interpenetram. Antes, aponta para a tensão existente entre os encontros discursivos e culturais. A categoria dialogia é de base na obra do Círculo e não se encontra específica e exclusivamente em uma dada obra. Neste artigo, focamos na dialogia entre economia e cultura.
} 
elaboração discursiva entre duas realidades históricas específicas, mas conectadas, selecionamos alguns excertos, delimitando, mormente, a temática do progresso técnico e tecnológico presente no referido manifesto, intentando perceber como o discurso literário formaliza esteticamente o mundo material, demonstrando como o homo simbolicus recria o homo faber. Esses termos latinos se referem a duas dimensões humanas conectadas desde os primórdios a partir de estudos antropológicos. O ser humano, para sobreviver, é um ser vocacionado para a técnica e o trabalho. O seu fazer material e concreto lhe possibilitou sobreviver às intempéries e perigos de toda sorte. O ser humano é aquele que fabrica ferramentas para escapar da morte e sobreviver. Entretanto, essa atividade é pensada e programada. Para tanto, precisa idealizar a atividade, ou seja, desenvolve formas simbólicas a partir da matéria que irá moldar (o ferro, a pedra, a madeira etc). O seu trabalho e o seu fazer precisam ser planejados anteriormente e no decorrer da atividade podem ser modificados, dependendo das condições de produção. O ser social age na matéria a partir da técnica e do trabalho e esses são planejados mediante o universo simbólico das imagens e das palavras. Nesse passo, a técnica e a linguagem se desenvolvem simultaneamente e são ontológicas, ou seja, constituem o humano, diferenciando-o dos outros animais e o transformando em ser social. A técnica e a linguagem são mediações para o ser humano se relacionar com o mundo material.

\section{Uma abordagem interdisciplinar, aliada à análise dialógica do discurso - ADD}

Este artigo ocorre mediante a interdisciplinaridade e pela Análise Dialógica do Discurso ADD. A partir desta, aproximamo-nos do Círculo russo. Nessa perspectiva, todo ato comunicativo, literário ou não, toma sentido na corrente comunicacional viva, inserido no contexto de produção. Vamos ler o corpus, percebendo-o em ligação com o contexto econômico. Importante frisar que para os filósofos do Círculo, o âmbito material, ou seja, o universo das condições concretas de existência deve integrar o estudo do discurso, haja vista que as condições enunciativas são dadas no cotidiano das relações econômicas e sociais. Seguindo essa orientação é que estabeleceremos as articulações entre infraestrutura e superestrutura. Essas interações ocorrem no sentido de mão dupla, não havendo determinabilidade de uma sobre a outra de modo dominante e exclusivo. Não se advoga a dominância do econômico sobre as ideias, mas uma dialogia ininterrupta entre os âmbitos ${ }^{6}$. Alguns pressupostos são fundantes na ADD, a saber: a noção de discurso em interpelação com o empírico, refletindo-o e refratando-o. Tomamos o discurso de Oswald como um posicionamento valorativo sobre o âmbito tecnológico. Na ADD, rejeita-se a ideia de certeza e verdade únicas sobre o objeto de pesquisa. Nossa leitura é uma interpretação da obra do poeta sob um certo prisma que se debruça sobre a reconstrução literária da tecnologia nacional. Neste viés, apregoa-se o caráter político e de intervenção social. O

\footnotetext{
${ }^{6}$ A esse respeito, consultar a terceira parte da obra de Bakhtin e Voloshinov (1986). A discussão é sobremodo esclarecedora dentro da tradição materialista e marxista uma vez que se afasta do dogmatismo econômico, trazendo a importância da ontologia da linguagem, dimensão relegada em boa parte dos estudos marxistas. Seguimos o Círculo, neste artigo.
} 
fato de trazer um tema menos estudado nas Letras, contribui para uma nova visão da obra de um clássico nacional. Interpretar a realidade nacional cultural e econômica junto com nossos alunos visa demonstrar que o Brasil pode participar das conquistas tecnológicas sem perder a sua identidade.

\section{Tecnologia e técnica e o discurso oswaldiano}

A técnica é vocação humana, pois o humano sobreviveu mediante a criação de aparatos técnicos para enfrentar os perigos que lhe assaltavam enquanto espécie. A pedra lascada, o fogo, a metalurgia, a agricultura, a pecuária, a roda, a imprensa, as ferrovias, os bondes, o automóvel, o telefone, a Internet etc são criações tecnológicas. Sabemos que muitas produções técnicas adentravam o Brasil nas primeiras décadas do século XX. Os escritores não se mantêm alheios a essa nova realidade que muitas vezes é enaltecida em suas obras ${ }^{7}$. Outras vezes, esse olhar entusiástico enfraquece e encontramos obras críticas acerca dessa produção. Acompanhando os desdobramentos da tecnologia, temos também o advento da linguagem, outra dimensão imprescindível para a sobrevivência humana. O ser humano associa-se a outro mediante, sobremodo, a sua capacidade de se comunicar. Tecnologia e linguagem são modos de o homem se relacionar com as coisas. A literatura, arte da palavra, também discursa, descreve, documenta como o ser humano produz tecnologia. O homo simbolicus se manifesta sobre o homo faber. A técnica, a tecnologia e a linguagem são condições humanas e mediações entre os humanos e as coisas. ${ }^{8}$ Nesse passo, entendendo tecnologia e linguagem como essenciais ao ser humano, buscaremos discutir a construção discursiva da técnica e da tecnologia ${ }^{9}$ no Manifesto Pau-Brasil.

Oswald viveu no período da primeira República em que a maquinaria adentrava o país com o surgimento de modo sistemático de indústrias e de um proletariado urbano de assalariados advindos sobretudo da Europa. Esse cenário tecnológico dos bondes, da energia elétrica, dos telégrafos, dos elevadores, dos automóveis, dos aviões não permanece ausente da Literatura

\footnotetext{
7 Sobre a representação literária da técnica e tecnologia na Literatura Brasileira, temos investigado, orientando mestrandos e doutorandos, essa temática. A investigação tem ocorrido há mais de década e tem recebido apoio do CNPq. Com foco em Oswald de Andrade, investigando outras obras, refiro a FANINI; MACIEL $(2013,2012)$ 8 Leroi-Gourhan (1964), antropólogo de bases materialistas, dedicado ao estudo das culturas, trata do dispositivo tecno-científico, apregoando as transformações técnicas enquanto inerentes ao construto social. Todavia, não descuida do estudo da linguagem humana, percebendo-a atrelada ao dispositivo e como meio de sobrevivência social. Técnica e linguagem são ontológicas para a condição humana.

${ }^{9}$ Por técnica entende-se a condição inerente ao ser humano em alterar o seu entorno e a si mesmo no sentido de sobreviver; já o termo tecnologia designa a manifestação epocal e histórica da técnica. Aquela é condição inerente ao homem, esta é a feição histórica daquela. Exemplo de tecnologia seria o advento da máquina a vapor na Revolução Industrial na Inglaterra, algo determinado por condições objetivas do século XVIII. A discussão ocidental sobre técnica e tecnologia é ampla e milenar. Para este artigo, nos embasamos em reflexões elaboradas no século XIX e XX. Marx (1986) traz a discussão de modo detalhado, analisando os impactos da tecnologia industrial sobre o trabalho e a cultura, demonstrando como a maquinaria altera o universo do trabalhador, degradando e intensificando a jornada laboral. Já Heidegger (1977) o faz, após a Segunda Guerra mundial, em contexto inóspito de escalada da tecnologia nuclear, analisando os perigos da técnica, bem como como suas vantagens. O estudo da Filosofia da técnica e da tecnologia é instigante e necessário. Oswald o faz via linguagem poética, contribuindo para a construção de um discurso sobre a técnica e a tecnologia em solo nacional.
} 
Brasileira. Em São Paulo, onde se encontra nosso escritor, ocorre, mais sistematicamente, no início do século XX, o processo de implantação de indústrias fabris e têxteis sobretudo, afastando-se o Brasil, em parte, de uma economia majoritariamente voltada para a exportação de bens primários, majoritariamente o café. Para essa implantação é necessário o trabalhador formalmente livre. Esse será buscado na Europa onde já estava inserido ao trabalho fabril. ${ }^{10}$ Decorrentes dessas alterações, se passa a questionar cada vez mais a formação do povo brasileiro e a sua identidade mestiça. Muitos intelectuais, embasados em teorias deterministas ${ }^{11}$, discutem a questão da degenerescência racial. As teorias do embranquecimento passam a ter voga. Muitos desejam apagar nosso passado indígena e africano, criando uma outra identidade europeia e branca para o país. O discurso literário vai dando conta dessas alterações sociais, apresentando-se como respostas a uma época. Oswald, como veremos, percebe as mudanças, sobretudo do cenário tecnológico brasileiro, mas não rejeita as raízes culturais e raciais locais que vão mobilizar esse universo de forma específica.

\section{0 discurso oswaldiano e a tecnologia: uma perspectiva dialógica}

Oswald cria certa visão sobre a tecnologia, em que as contradições, as junções e disjunções são partes constituintes da História do Brasil. Essa História surge em confronto e articulação com nossos colonizadores e com outras nações com as quais o Brasil mantinha relações econômicas, culturais e diplomáticas. Essa trajetória histórica de encontros e desencontros consiste em perceber não apenas o processo pacífico de aculturação aos moldes importados, mas revela os confrontos, as insurgências, as permanências da cultura e história local em tensa inter-relação com o que nos vem de fora. Essa perspectiva, como salientamos, se institui mediante uma certa visão antropofágica em que não anulam ou superam os contrários, mas se constitui em um processo ininterrupto de encontro e desencontro. Aproxima-se de uma perspectiva de carnavalização em que impera esse movimento ininterrupto de junções e disjunções. Tomamos o termo carnavalização de Bakhtin (1987), cuja obra se volta, sobretudo, para a análise de um corpus não canônico: a cultura popular do riso popular e do povo humilde, contraposta à cultura oficial daqueles que detêm o poder político e econômico. O filósofo russo trata das festas carnavalescas (remonta-as à Antiguidade grega, vindo até o Renascimento, sobremodo), encontrando aí práticas de resistência popular à cultura oficial. Esse espaço festivo não é estudado para se descrever de modo formal ou estrutural o carnaval, mas para demonstrar que aí residem formas de resistências populares que possibilitam se criar meios de enfrentar os desmandos do poder. O riso blasfêmico, o tempo e o espaço do ócio e do não trabalho, a

\footnotetext{
10 Foram consultadas obras da historiografia, nos âmbitos da dimensão econômica, política e cultural, presentes em Furtado (1908), Fausto (2002), Iglésias (1986), Prado Jr. (2006) e Carvalho (1990). Essas vozes historiográficas nos auxiliam para entender, juntamente com Oswald, o período da República Velha.

11 Consultar Schwarcz (1993) que trata das discussões sobre mestiçagem, política de embranquecimento, teorias eugenistas, de orientação monogenista e poligenista, que acirravam os ânimos nas faculdades de Direito e Medicina, no final de oitocentos. Essa discussão adentrou o século XX, sendo suporte para o Arianismo, presente, no movimento integralista.
} 
desentronização temporária da hierarquia social são expedientes carnavalescos que desestabilizam as posições sociais fixas. São uma tomada de consciência das classes populares para uma ação efetiva de desmobilização do autoritarismo das elites. Pobres e nobres viam a realidade de modo diverso e isso se concretizava nas festas de Carnaval. Com o advento da Revolução Industrial e fortalecimento da cultura burguesa do enaltecimento do trabalho sistemático e da vida regularizada para a atividade laboral, as festas populares se tornam escassas visto que o trabalhador não pode desperdiçar o seu tempo na festa. Embora haja uma neutralização dessas festas, esse espírito de liberdade não se apaga. Bakhtin o percebe na arte como um expediente que enforma certas visões de mundo críticas a que os escritores aderem em menor ou maior grau. Ocorre o enfraquecimento do carnaval nas ruas mediante a obrigatoriedade do trabalho, intensificado, regrado e desumanizante, nas fábricas, mas nas artes, o expediente passa a ser uma importante arma de resistência.

Vemos que a "antropofagia" se aproxima da "carnavalização" visto que Oswald se volta para a cultura do cotidiano do povo, dos indígenas e dos africanos, recuperando-as e recriando-as. Mesmo que o termo antropofagia não ocorra antes de Manifesto Antropófago, por meio do qual Oswald radicaliza a perspectiva axiológica de matriz antropofágica, percebemos que, já em nosso corpus de estudo, o escritor molda a sua visão de mundo em certa consonância com a perspectiva antropofágica que irá esclarecer mais adiante. Oswald não teorizou sobre a antropofagia, nos moldes bakhtinianos, em um tratado teórico sistemático, mas o faz, com certeza, mediante sua resposta literária. Podemos afirmar que há, sim, uma teorização literária, sobretudo nos manifestos. O escritor concretiza a sua visão antropofágica diretamente em sua obra artística, construindo o seu discurso sobre a realidade brasileira mediante uma perspectiva dialógica que comporta o dualismo, todavia não dicotomizado. Perceba-se que tanto Bakhtin quanto Oswald, embora em cronotopos diversos, assemelham-se quanto a uma visão de mundo dialógica e carnavalizada para aquele e antropofágica para este. Acreditamos que os dois intelectuais se conectam axiologicamente e, por isso, valemo-nos das categorias bakhtinianas para entender melhor a perspectiva oswaldiana.

\section{Uma leitura do discurso sobre a tecnologia brasileira no Manifesto Pau-Brasil}

Percebemos que Oswald trabalha com paralelismos, antíteses, contradições, mas que em vez de se acentuar a dicotomia, destaca-se o dialogismo. Há uma substantiva intercessão dos contrários, como se fossem, ora dois conjuntos diversos, mas com áreas que se interpenetram, como uma moeda, cujos lados de cara e coroa se distinguem perfeitamente, mas inteiram o todo de modo indissolúvel ${ }^{12}$. A identidade nacional é definida como "Pau-Brasil”. O vocábulo

\footnotetext{
${ }^{12} \mathrm{O}$ estudo da epistemologia dialética é complexo. A cada conjunto de ideias, por exemplo, do campo estruturalista, marxista e fenomenológico, promana uma certa perspectiva diversa da dialética enquanto forma de conhecimento. Neste artigo, em decorrência do corpus estudado, destacamos que Oswald percebe o mundo mediante uma dialética em que os polos contrários não se anulam em síntese harmoniosa. Antes, vivem em constante luta, formando um todo instável, sobretudo em relação às articulações entre modelos importados e realidade local. Não
} 
"Pau-Brasil" sinaliza uma maneira de se manifestar a poesia brasileira. O vocábulo, no entanto, não se atrela somente a um novo modo poético. A expressão é polissêmica, remetendo também para o primeiro ciclo econômico do capital comercial de exploração dos colonizadores portugueses. Sabe-se que os ciclos econômicos fizeram parte da empreitada dos colonizadores, sendo nos primórdios uma economia de exportação, dirigida para fora e pouco restando de progresso interno ${ }^{13}$. O universo de extração de matéria prima se utilizou de tecnologia básica, majoritariamente do esforço laboral de índios e africanos escravizados. Os equipamentos de extração são simples e dependem da força física dos trabalhadores. Já a circulação do material (Pau-Brasil, café, pedras preciosas, ouro, café, cacau, algodão etc), sobretudo aquele levado do Brasil para outras nações, contou com tecnologia de transporte sofisticada. Porém essa tecnologia não rendeu ganhos para a população trabalhadora local, inclusive porque o trabalho era compulsório. A dimensão literária nos traz o cotidiano de trabalhadores que labutam nessa faina, reconstruindo o dia a dia da existência material, demonstrando que são homens simples que operam as máquinas, sendo esses que vão construindo riquezas, sem contudo delas usufruir: "As procissões saíram novinhas das fábricas" (ANDRADE, 2016, n. p). Nessa sucinta frase, o poeta nos traz os trabalhadores que adentram as fábricas. Remete-se ao trabalho fabril, mas este é dado também em chave religiosa a partir do vocábulo "procissão". O trabalhador está voltado para a racionalidade técnica do labor, mas permanece vinculado ao âmbito transcendente. Ocorre a contradição dos termos, o que é uma constante no corpus estudado. As fábricas são objeto estético, mas as casas populares também, explicitando as contradições do capital. A tecnologia avançada com maquinário importado não beneficia o trabalhador brasileiro que continua a viver de modo precário. Oswald recria essas disjunções materiais: "Os casebres de açafrão e de ocre nos verdes da Favela, sob o azul cabralino, são fatos estéticos" (ANDRADE, 2016 , n. p). Oswald se se utiliza de vocábulos absolutizantes como "toda" e "tudo", recriando o universo extraliterário de forma inclusiva onde o lado econômico e o cultural se interpenetram. Repete-se o vocábulo "toda" em torno de sete vezes, frisando uma denominação que remonta ao passado, mas que está presente no contexto imediato do autor. Há uma continuidade histórica, cultural e econômica e essa se faz de contradições. Não são dicotomias, pois fazem parte de um todo em que os polos se interpenetram, formando um conjunto indissolúvel. Tanto a carnavalização quanto a antropofagia operam nessa eterna agonística dos opostos, sem uma síntese que harmonize o cenário das oposições.

O progresso técnico aparece em várias passagens, demonstrando as alterações tecnológicas por que passava o período da República Velha com o advento, principalmente das indústrias, mas esse progresso está associado à cultura local que pode tanto reafirmá-lo como desvirtuá-

há uma dialética abstrata e mecanicista, nem uma dicotomia irredutível entre os polos. Antes, como temos asseverado, há uma dialogia.

${ }^{13}$ A esse respeito pode-se consultar o clássico do economista Prado Junior (2006) de tradição marxista, em que se discute o sentido da economia colonial, imperial e republicana até a década de 30 do século XX. Aí se destaca o caráter do sentido externo de nossa economia, não se desenvolvendo bens internos industriais de monta. A maquinaria na República Velha é importada, sendo nacionalizada a partir do governo de Getúlio Vargas, cujo projeto nacional impulsionou os bens da indústria de base. Consultar também Furtado (1980) que segue, majoritariamente, essa tese, chamando a atenção sobre a alteração do cenário econômico somente no século XX, na década de 50 em diante, quando se implanta a política desenvolvimentista que contradiz a economia exclusiva para fora. 
-lo, revelando os desníveis, carnavalizando-o. Perceba-se que a tecnologia importada vai ser recontextualizada pelo cenário laboral, destacando-se as contradições. No excerto a seguir, a tecnologia importada do maquinário ferroviário pode descarrilhar ou se desviar visto que será operada por trabalhadores locais que podem modificar o seu rumo e propósito: “Tendes as locomotivas cheias, ides partir. Um negro gira a manivela do desvio rotativo em que estais. O menor descuido vos fará partir na direção oposta ao vosso destino" (ANDRADE, 2016, n. p.). O Brasil, no período da escrita do Manifesto, é ainda majoritariamente exportador de café, produto que sustenta a economia nacional, inclusive a indústria fabril e têxtil é caudatária do excedente de capital da exportação cafeeira ${ }^{14}$. As locomotivas estão cheias de produto de exportação. A matéria prima é nacional, mas o meio de transportá-la é importado. Pode haver o descompasso entre o local e o externo, como atesta o excerto. $\mathrm{O}$ trabalhador que opera a máquina, no caso a locomotiva, pode desviá-la de seu rumo uma vez que a cultura local não assimila ipsis litteris a cultura e a economia importadas. Esse dualismo está presente em toda a obra, indicando uma tensão entre o progresso técnico advindo das ciências exatas aplicadas de origem europeia e a tradição cultural brasileira diversa em que outros componentes imperam, como atesta o fragmento: "Temos a base dupla e presente - a floresta e a escola. A raça crédula e dualista e a geometria, a álgebra e a química logo depois da mamadeira e do chá de erva-doce. Um misto de 'dorme nenê que o bicho vem pegá' e de equações" (ANDRADE, 2016, n. p.). Vemos que a ciência convive com crenças e hábitos cotidianos que constituem uma cultura local de longa duração. Esse desvio também indica uma forma de resistência local do trabalhador. No momento da escritura do Manifesto, não há mais a escravidão africana. $\mathrm{O}$ trabalhador europeu adentra a indústria, mas o alforriado e liberto também. A historiografia mais recente sobre a questão africana no Brasil ${ }^{15}$ demonstra que a resistência negra se valia de diversas estratégias, inclusive, sabotando a maquinaria das fazendas, reinventando o ludismo em bases nacionais. Desse modo, o desvio da máquina sinaliza para uma estratégia de resistência do trabalhador brasileiro a uma tecnologia operada por ele, mas que lhe degradava a vida em trabalho estafante e pouco remunerado.

A referência ao progresso técnico se dá pela nomeação de vários aparatos tecnológicos urbanos já integrados na paisagem de São Paulo, mas em sintonia e contradição com a realidade local tradicional. Comparecem no Manifesto tanto o capitalismo produtivo atrelado à maquinaria importada - como "os cilindros dos moinhos" e "as turbinas elétricas" -, quanto o capitalismo financeiro que integrava o Brasil aos centros europeus e americano, apoiado nas "questões cambiais" (ANDRADE, 2016, n. p.).

O progresso tecnológico altera o cenário nacional e não passa despercebido do escritor que o manifesta atrelado a uma cultura que lhe é estranha. A prática da "reza", remete ao catolicismo

\footnotetext{
${ }_{14}$ Sobre o sentido da economia voltada para fora, consultar novamente as obras já citadas de Prado Junior (2006) e Furtado (1980).

15 Seguimos MATTOSO (1999) e SLENES (2011), da nova historiografia que trata da questão escrava no Brasil, advogando a tese de que sempre houve resistência negra ao cativeiro. Segundo os autores, essa agência se desenvolvia por meio de expedientes vários desde a revolta individual até a coletiva. O escravo não foi coisa, mas agente no processo, embora submetido ao sistema econômico de trabalho compulsório.
} 
brasileiro que se opõe à visão materialista do progresso tecnológico associado à visão científica e dessacralizadora do mundo. A "saudade dos pajés" faz parte de uma cultura nacional que resiste ao materialismo, avesso a soluções de ordem transcendental. O "carnaval" e "o sabiá" integram o tempo e o espaço da festa, da música, da suspensão do trabalho padronizado das indústrias e da maquinaria. O cenário maquinístico se vincula a São Paulo, cidade industrializada, mas integra todos os brasileiros a uma dada identidade entre o novo e o velho, a tradição e a tecnologia. No trecho a seguir temos: "Apenas brasileiros de nossa época. O necessário de química, de mecânica, de economia e de balística. Tudo digerido. Práticos. Experimentais. Poetas. Sem reminiscências livrescas. Sem comparações de apoio. Sem pesquisa etimológica. Sem ontologia" (ANDRADE, 2016, n. p.). A identidade brasileira se manifesta tanto como capaz de se relacionar com o mundo via poesia quanto pela ciência. No trecho a seguir, novamente o escritor insiste na dimensão poética, mas vinculada à dimensão tecnológica: "A reação contra todas as indigestões de sabedoria. O melhor de nossa tradição lírica. O melhor de nossa demonstração moderna" (ANDRADE, 2016, n. p.).

Outra expressão reiterada é "Museu nacional", que aponta para a tensão entre a cultura local de longa duração e o presente de inovações tecnológicas. Esse "museu" é ambíguo, pois sinaliza ora para a tradição, mas contém o presente, assim como abriga a natureza brasileira que produz matéria prima para a economia de exportação. $\mathrm{O}$ trecho a seguir atesta esses paralelismos que se imbricam dialogicamente, reforçando uma axiologia dos opostos: "Bárbaros, crédulos, pitorescos e meigos. Leitores de jornais. Pau-Brasil. A floresta e a escola. O Museu Nacional. A cozinha, o minério e a dança. A vegetação. Pau-Brasil" (ANDRADE, 2016, n. p.). O lado do progresso técnico e as importações de ideias são inevitáveis e até benvindos, afastando-se de uma visão xenófoba. O poeta percebe o Brasil integrado ao contexto europeu, mas essa integração ocorre com resistências, pois nosso passado, matrizes raciais, crenças, religiosidade popular, culturas indígena e africana também instituem essa construção identitária e alteram o presente e a modernidade do progresso técnico. Não há uma demonia da técnica e da tecnologia ${ }^{16}$. Nos seguintes fragmentos, Oswald expõe os reveses que a cultura importada sofre, sem, contudo, ser neutralizada. Há um entronizar e um desentronizar do que parece alheio mediante um movimento dinâmico em que o local se manifesta de modo ativo: "O trabalho da geração futurista foi ciclópico. Acertar o relógio império da literatura nacional. Realizada essa etapa, o problema é outro. Ser regional e puro em sua época" (ANDRADE, 2016, n. p.).

Em outro excerto, o poeta explicita a conjunção entre o externo, dado por aparato tecnológico importado e a sua filtragem local, resultando no amálgama nacional. Não há uma negação desse progresso técnico, mas uma assimilação, que o recria em outras bases. A infraestrutura, ou seja, a base material e técnica, é agregada à superestrutura, representada por uma certa cultura histórica específica e ao cotidiano social. Dessa conjunção nasce a cultura e a sociedade "Pau-Brasil", que se institui pela confluência de contradições (o trabalho formal e técnico

\footnotetext{
${ }_{16}$ Heidegger (1977) trata da necessidade de se enxergar a técnica de modo reflexivo. Distancia-se de uma demonização da técnica, levando-nos a perceber a urgência de se questionar a tecnologia em suas manifestações culturais e econômicas a fim de não se deixar englobar por uma unidimensionalidade tecnicista. Oswald plasma uma perspectiva sobre a técnica não demonizada, apresentando-a como manifestação cultural enraizada na história local.
} 
versus a preguiça; a racionalidade versus o sentimentalismo; a natureza versus a técnica; a luz elétrica versus a luz solar; o passado versus o presente; a impessoalidade dos negócios versus a familiaridade):

Uma visão que bata nos cilindros dos moinhos, nas turbinas elétricas, nas usinas produtoras, nas questões cambiais, sem perder de vista o Museu Nacional. Pau-Brasil.

Obuses de elevadores, cubos de arranha-céus e a sábia preguiça solar. A reza. O Carnaval. A energia íntima. O sabiá. A hospitalidade um pouco sensual, amorosa. A saudade dos pajés e os campos de aviação militar. Pau-Brasil. (ANDRADE, 2016, n. p.)

Finalizando nossa análise, recorremos a um último fragmento em que se alia a cultura do riso, da tradição, da religiosidade, da pluralidade étnica ao capitalismo comercial de exportação e ao advento das siderurgias. Perceba-se que a cosmovisão carnavalizada se destaca nessas polarizações, mas em constante dialogia, ou seja, não se anulam os contrários em uma síntese superadora:

O Carnaval no Rio é o acontecimento religioso da raça. Pau-Brasil. Wagner submerge ante os cordões de Botafogo. Bárbaro e nosso. A formação étnica rica. Riqueza vegetal. O minério. A cozinha. O vatapá, o ouro e a dança. (ANDRADE, 2016, n. p.)

A linguagem não engloba só o âmbito cultural, mas também o material, surgindo o Brasil como produtor de minérios, matéria prima de exportação dentro de relações comerciais capitalistas internacionais. O universo superestrutural local surge como uma força de resistência ao campo infraestrutural da vida material.

\section{Considerações finais}

Este artigo focou a questão da tecnologia importada trazida para o Brasil, mormente da Europa, no período da República Velha, investigando como Oswald de Andrade integrou discursivamente essa realidade tecnológica ao seu discurso literário. Oswald vê essa realidade de maneira dialógica, elaborando um retrato do país mediante uma perspectiva dual em que a cor local se manifesta a partir das tradições que remontam ao passado colonial e imperial, abarcando também uma certa cultura popular e do cotidiano em que a religiosidade, as crenças, as superstições entram em confronto e em sintonia com a modernidade tecnológica. Desse confronto dinâmico surge uma certa identidade nacional fruto de realidades polarizadas, mas que se interpenetram. O recurso da dialogia consiste em que se demonstram os impasses, desníveis e disjunções dessa polarização, mas também a possível coexistência dos contrários.

\section{REFERÊNCIAS}

ANDRADE, Oswald. Manifesto Antropófago. Disponível em: <http://zonacurva.com.br/o-manifesto-antropofagico-de-oswald-de-andrade/>. Acesso em: 26 dez 2015. 
ANDRADE, Oswald. Manifesto Pau Brasil. Disponível em: <http://zonacurva.com.br/o-manifesto-paubrasil-de-oswald-de-andrade/>. Acesso em: $26 \mathrm{dez} 2016$.

ASSIS, Machado de. Obra completa em quatro volumes. v. 3, Rio de Janeiro: Nova Aguilar 2008.

BAKHTIN, Mikhail. Cultura popular na Idade Média e no Renascimento: o contexto de François Rabelais. Trad. Yara Frateschi Vieira. São Paulo: Hucitec/Editora Universidade de Brasília, 1987.

BAKHTIN, Mikhail; VOLOSHINOV, Valentim. Marxismo e Filosofia da linguagem. Trad. Michel Lahud e Yara Frateschi Vieira. São Paulo: Hucitec, 1986.

BAKHTIN, Mikhail. Estética da criação verbal. Trad. Maria E. G. G. Pereira. São Paulo: Martins Fontes, 1977.

BAKHTIN, Mikhail. Questões de literatura e estética: a teoria do romance. Trad. Aurora Fornoni Bernardini et al. São Paulo: Editora Hucitec, 1988.

BOSI, Alfredo. A escravidão entre dois liberalismos. In: BOSI, Alfredo. Dialética da colonização. São Paulo: Companhia da Letras, 1992. Cap. p.194-245.

CANDIDO, Antonio. Formação da Literatura Brasileira (Movimentos decisivos). 6. ed. v.2. Belo Horizonte: Ed. Itatiaia, 1981.

CANDIDO, Antonio. Literatura e subdesenvolvimento. In: CANDIDO, Antonio. A educação pela noite \& outros ensaios. São Paulo: Ática, 1987.

CARVALHO, José Murilo de. A formação das almas: o imaginário da República no Brasil. São Paulo: Companhia das Letras, 1990.

FANINI, A. M. R.; MACIEL, A. P. O Universo Multifacético da Tecnologia na peça O Homem e o Cavalo de Oswald de Andrade. Repertório: Teatro \& Dança (Online), v. 20, p. 89-101, 2013.

FANINI, A. M. R.; MACIEL, A. P. O Rei da vela de Oswald de Andrade e a representação simbólica do contexto industrial e tecnológico brasileiro. Revista Soletras, v. 24, p. 223-233, 2012.

FAUSTO, Boris. História concisa do Brasil. São Paulo: Edusp, 2002.

FURTADO, Celso. Formação econômica do Brasil. 17. ed. São Paulo: Companhia editora do Brasil, 1980.

HEIDEGGER, Martin. The questioning concerning technology. New York: Harper, 1977.

IGLÉSIAS, Francisco. A industrialização brasileira. São Paulo: Brasiliense. 1986.

LEROI-GOURHAN. André. O gesto e a palavra - 1. Técnica e linguagem. Lisboa Edições 70. 1964, Cap. V, pp. 147-168.

KARL, Marx. A Maquinaria e a Indústria Moderna. In: KARL, Marx. O capital: crítica da economia política. Trad. Reginaldo Santanna.12 ed. Trad. Reginaldo Santanna. Rio de Janeiro: Bertand, 1986. Cap. p. 423-576.

MATTOSO, Katia Queiros de. Ser escravo no Brasil. 2. ed. São Paulo: Brasiliense, 1990.

PRADO JR., Caio. História econômica do Brasil. 47 ed. São Paulo: Editora Brasiliense, 2006.

SCHWARZ, Roberto. Ao vencedor as batatas: forma literária e processo social nos inícios do romance brasileiro. 34. ed. São Paulo: Duas Cidades, 2000. 
SCHWARCZ, Lilia Moritz. O espetáculo das raças: cientistas, instituições e questão racial no Brasil - 18701930. São Paulo: Companhia das Letras, 1993.

SLENES, Roberto W. Na senzala, uma flor: esperanças e recordações na formação da família escrava. Campinas: Ed. da Unicamp, 2011. 